\title{
Fast-track endovascular aneurysm repair: rationale and design of the multicenter Least Invasive Fast-Track EVAR (LIFE) registry
}

Zvonimir Krajcer $^{1 *}$, Venkatesh Ramaiah ${ }^{2}$ and Meredith Huetter $^{3}$

\begin{abstract}
Background: Considerable technological advancements have recently been made with endovascular stent grafts for the treatment of abdominal aortic aneurysm (AAA). However, there is opportunity to further improve the efficiency of endovascular aneurysm repair (EVAR), which may yield better patient outcomes and lower perioperative treatment costs.

Methods/Design: The Least Invasive Fast-Track EVAR (LIFE) registry was developed to determine the clinical utility and cost effectiveness of the Ovation ${ }^{\oplus}$ Prime stent graft when used under least invasive conditions using a defined fast-track protocol. The LIFE study is a prospective multicenter post-market registry of the ultra-low profile (14F) Ovation Prime stent graft when used in the treatment of patients with AAA using a fast-track protocol, consisting of appropriate patient selection, bilateral percutaneous access, avoidance of general anesthesia and intensive care unit admission, and next-day discharge. The primary endpoint of the study is the proportion of subjects that experience a major adverse event within 30 days of the initial procedure. Primary endpoint data will be compared to a target performance goal. A total of 250 subjects will be enrolled at up to 40 sites in the United States. The first subject in this study was enrolled in October 2014 and enrollment is anticipated to continue through mid-2016.
\end{abstract}

Discussion: The recent development of ultra low-profile stent grafts enables EVAR using least invasive methods. A structured fast-track EVAR protocol may yield clinical and cost benefits versus standard EVAR.

Trial registration: ClinicalTrials.gov Identifier: NCT02224794

Keywords: Abdominal aortic aneurysm, Endovascular, Fast-track, Ovation, Protocol, Stent graft

\section{Background}

Over the last decade, considerable advancements have been made with endovascular stent grafts for the treatment of abdominal aortic aneurysm (AAA). Early studies with endovascular aortic repair (EVAR) demonstrated significantly lower perioperative morbidity and mortality rates compared to open surgical resection [1]. Consequently, EVAR has rapidly become the standard of care for AAA repair at most centers. Studies with latest-generation

\footnotetext{
* Correspondence: zvonkomd@aol.com

'St. Luke's Episcopal Hospital, Houston, TX, USA

Full list of author information is available at the end of the article
}

stent grafts have focused on improving treatment durability and expanding EVAR eligibility to accommodate patients with challenging aortoiliac anatomy. Despite this recent progress, considerable opportunity exists to further improve the efficiency of EVAR, which may yield even better patient outcomes and lower perioperative treatment costs.

Typical EVAR cases involve vascular access via surgical exposure of the common femoral artery, general anesthesia, a 24-h intensive care unit (ICU) stay, and a 3-day hospitalization [2], all of which increase morbidity and significantly contribute to the total cost of EVAR. In the current economic climate, there is heightened scrutiny on health care resource utilization such that opportunities 
for improved surgical- and hospital-related efficiency must continue to be explored. Fast-track hospital care pathways have been adopted with increasing frequency for open aortic surgery, resulting in shorter ICU $[3,4]$ and hospital $[5,6]$ stays with reductions in morbidity $[3,4,6]$ compared to traditional surgical practices. However, experience with fast-track EVAR remains limited. The common premise of fast-track EVAR includes well-selected patients with low-risk of periprocedural complications, bilateral percutaneous vascular access, and regional anesthesia with or without conscious sedation, all of which enable faster patient recovery and expedite hospital discharge. The largest study of fast-track EVAR involved 915 patients treated with bilateral percutaneous access and local anesthesia/conscious sedation [7]. Treatment success was achieved in $94 \%$ of cases, mean hospital stay was 1.3 days, and 30-day mortality was only $0.6 \%$. The clinical and cost benefits associated with fast-track EVAR are potentially substantial, but currently are not well characterized. The Least Invasive Fast-Track EVAR (LIFE) registry was developed to explore the clinical utility and cost effectiveness of a defined fast-track EVAR protocol in patients undergoing elective AAA repair.

\section{Methods/Design}

The LIFE registry is a prospective, nonrandomized, multicenter post-market study that will enroll 250 patients at up to 40 sites in the United States. The protocol for this clinical trial has been approved by the institutional review board (IRB) at each participating site. Recruitment is ongoing and additional sites, up to 40 total sites, will be added to those already named in Table 1 . All patients provided informed consent before study participation. Patient enrollment began in October 2014. This study was prospectively registered at www.clinicaltrials.gov (NCT02224794).

\section{Participants}

Eligible patients are adults with AAA requiring elective intervention who have anatomy suitable for endovascular repair. Complete inclusion and exclusion criteria are reported in Table 2. Pre-treatment assessments will include medical and surgical history, laboratory tests for creatinine and pregnancy, spiral contrast-enhanced computed tomography, and questionnaires related to groin pain severity and health-related quality of life. Patients will be enrolled and treated with EVAR if the investigator determines that bilateral percutaneous access, avoidance of general anesthesia and ICU stay, and next-day hospital discharge are feasible based on medical history and aortoiliac anatomy. Following enrollment, patients will remain in the study regardless of whether all components of the fast-track program are completed. Patient outcomes will be recorded through hospital
Table 1 Study Sites and Institutional Review Board

\begin{tabular}{|c|c|}
\hline Site Name & Institutional Review Board \\
\hline $\begin{array}{l}\text { Central Arkansas Veterans } \\
\text { Healthcare System }\end{array}$ & $\begin{array}{l}\text { Central Arkansas Veterans Healthcare } \\
\text { System IRB }\end{array}$ \\
\hline NCH Healthcare Systems & $\mathrm{NCH}$ IRB \\
\hline Temple University Hospital & WIRB \\
\hline Wellmont Holston Valley MC & Wellmont Health System IRB \\
\hline Morton Plant Hospital & BayCare Health System IRB \\
\hline Swedish Heart and Vascular & WIRB \\
\hline Bend Memorial Clinic & WIRB \\
\hline Hartford Hospital & Hartford Health Care IRB \\
\hline WVU Hospital & West Virginia University IRB \\
\hline St. Luke's Episcopal Hospital & BRANY IRB \\
\hline Palomar Medical Center & WIRB \\
\hline SIH Memorial Hospital & $\mathrm{SIH} I \mathrm{RB}$ \\
\hline Sutter Memorial Hospital & WIRB \\
\hline Chandler Regional Medical Center & East Valley Regional IRB \\
\hline Syracuse VA Medical Center & Syracuse VAMC IRB \\
\hline Southern Ohio Medical Center & Southern Ohio Medical Center IRB \\
\hline $\begin{array}{l}\text { Jersey Shore University Medical } \\
\text { Center }\end{array}$ & WIRB \\
\hline St. Joseph Mercy Oakland & St. Joseph Mercy IRB \\
\hline Phoenix St. Luke's Medical Center & WIRB \\
\hline $\begin{array}{l}\text { Medical University of South } \\
\text { Carolina }\end{array}$ & MUSC IRB III \\
\hline OhioHealth Research Institute & WIRB \\
\hline Arizona Heart Institute & WIRB \\
\hline Heart Hospital of New Mexico & WIRB \\
\hline Tuscon Medical Center & WIRB \\
\hline Harrison Medical Center & WIRB and Harrison Medical Center IRB \\
\hline Bakersfield Heart Hospital & WIRB \\
\hline Saint Jospeh Hospital & WIRB \\
\hline Lutheran Medical Center & Lutheran Medical Center IRB \\
\hline Middlesex Hospital & Middlesex Hospital IRB \\
\hline Sacred Heart Hospital & Sacred Heart Clinical IRB \\
\hline $\begin{array}{l}\text { Memorial Hospital of Jacksonville } \\
\text { (FCCI) }\end{array}$ & WIRB \\
\hline Gwinnett Medical Center & WIRB \\
\hline Scottsdale Healthcare-Osborn & WIRB \\
\hline $\begin{array}{l}\text { Northern Michigan Regional } \\
\text { Hospital }\end{array}$ & WIRB \\
\hline
\end{tabular}

discharge and at the 30-day follow-up visit per the schedule of activities in Table 3.

\section{Device}

The endograft under study is ideally suited for use in a fast-track EVAR program. The Ovation Prime stent graft is characterized by a tri-modular design with the aortic 
Table 2 Main study entry criteria

\begin{tabular}{|c|}
\hline Main inclusion criteria \\
\hline- Age $\geq 18$ years \\
\hline - Male or non-pregnant female \\
\hline - Candidate for elective open surgical AAA repair \\
\hline $\begin{array}{l}\text { - AAA }>5.0 \mathrm{~cm} \text { diameter, increased } \geq 0.5 \mathrm{~cm} \text { diameter in last } 6 \text { months, } \\
\text { or maximum diameter }>1.5 x \text { adjacent non-aneurysmal aorta }\end{array}$ \\
\hline $\begin{array}{l}\text { - Suitable anatomy for endovascular repair with the Ovation Prime } \\
\text { Stent Graft }\end{array}$ \\
\hline $\begin{array}{l}\text { - Suitable anatomy to allow Perclose ProGlide Suture-Mediated } \\
\text { Closure System via the pre-close technique }\end{array}$ \\
\hline Main exclusion criteria \\
\hline - Dissecting or acutely ruptured AAA \\
\hline - Acute vascular injury \\
\hline - Prior AAA or iliac artery repair \\
\hline - Mycotic AAA or active systemic infection \\
\hline - Unstable angina \\
\hline - Unstable peripheral artery disease with critical limb ischemia \\
\hline - Congestive heart failure \\
\hline - Myocardial infarction or stroke within the past 3 months \\
\hline - Need for renal artery coverage (e.g. Chimney graft) \\
\hline - Planned adjunctive devices (e.g. renal stent) \\
\hline - Major surgery or interventional procedure within the past 30 days \\
\hline - Connective tissue disease (e.g. Marfan's or Ehler's-Danlos syndrome) \\
\hline - History of bleeding disorder or refuses blood transfusions \\
\hline - Dialysis-dependent renal failure or serum creatinine $>2.0 \mathrm{mg} / \mathrm{dl}$ \\
\hline - Morbid obesity (BMl $\geq 40 \mathrm{~kg} / \mathrm{m}^{2}$ ) \\
\hline - Home oxygen use \\
\hline - Patient admitted from skilled nursing facility \\
\hline - Life expectancy $<1$ year \\
\hline - Anticipated inability to discharge patient within 1 day \\
\hline - Participation in investigational device or drug clinical trial \\
\hline $\begin{array}{l}\text { - Intolerance/hypersensitivity to anticoagulation, contrast media, or } \\
\text { stent graft components }\end{array}$ \\
\hline
\end{tabular}

body delivered via a flexible hydrophilic-coated 14 Fr OD catheter, the smallest profile of any currently commercially available stent grafts. The aortic body is comprised of a low permeability PTFE graft and a suprarenal nitinol stent with integral anchors to achieve active fixation to the aortic wall. The aortic body contains a network of inflatable channels and sealing rings that are filled during deployment with a low viscosity, radiopaque fill polymer that cures in situ to create a conformable seal to the aortic neck. The Ovation Prime iliac limbs are comprised of highly flexible nitinol stents encapsulated in low-permeability PTFE that are packaged in ultra-low profile 13-14F OD delivery system.

\section{Outcomes}

The primary endpoint of the LIFE registry is the incidence of major adverse events through 30 days follow-up. Major adverse events are defined as any of the following events: death, myocardial infarction, stroke, renal failure, respiratory failure, paralysis, bowel ischemia, or procedural blood loss $\geq 1000 \mathrm{cc}$. All adverse events will be adjudicated by a Clinical Events Committee (CEC). Secondary endpoints of the LIFE registry include operative details, technical success, procedure- and device-related complications, patient convalescence, and ability to successfully complete all components of the fast-track protocol (Table 4). Patients will be followed in the LIFE registry for 30 days posttreatment and will undergo lifelong surveillance thereafter. A 30-day primary endpoint is appropriate since the benefits of a fast-track EVAR program are anticipated to be realized entirely in the perioperative period.

\section{Hypothesis}

The primary hypothesis of the LIFE registry is that the incidence of major adverse events through 30 days will be less than a target performance goal (TPG) of $10.4 \%$. The TPG was determined by using the $95 \%$ upperbound confidence interval of the 30-day major adverse event rate in the Ovation pivotal trial (5.4\%) [8] and adding a $5 \%$ margin.

Table 3 Schedule of study activities

\begin{tabular}{|c|c|c|c|c|}
\hline Procedure & Baseline & Procedure & Post-Procedure & 1 Month \\
\hline Medical/surgical history & $x$ & & & \\
\hline Spiral contrast-enhanced $\mathrm{CT}$ & $x$ & & & $x$ \\
\hline Laboratory assessment (creatinine, serum pregnancy) & $x$ & & & \\
\hline Quality of life (EQ-5D) & $x$ & & & $x$ \\
\hline Groin pain (Wong-Baker FACES Pain Rating Scale) & $x$ & & $x$ & $x$ \\
\hline Endovascular AAA repair & & $x$ & & \\
\hline Adverse events & & $x$ & $x$ & $x$ \\
\hline Assessment of ambulation and normal diet & & & $x$ & \\
\hline
\end{tabular}


Table 4 Secondary endpoints

- Serious and non-serious adverse events
- Access technical success (i.e. procedure successfully completed with
bilateral percutaneous access)
- Treatment success (i.e. successful completion of least invasive protocol
through discharge)
- Blood loss, including if transfusion required
- Percent of procedures completed without general anesthesia
- Anesthesia time
- Procedure time
- Contrast volume
- Fluoroscopy time
- Time to hemostasis
- Time to ambulation
- Time to normal diet
- Groin pain
- Quality of life
- Percent of subjects discharged without ICU admission
- Length of ICU stay, if required
- Length of hospital stay
- Percent of subjects discharged within only one overnight stay
- Freedom from type I \& III endoleak
- Freedom from AAA rupture
- Freedom from conversion to open repair
- Freedom from AAA-related secondary interventions
- Freedom from mortality

\section{Statistical methods}

The sample size for the LIFE registry was determined using the exact binomial method based on a one-sided $5 \%$ significance level, an anticipated $5 \%$ major adverse event rate, and no more than $20 \%$ attrition. Based on these assumptions, a sample size of 250 subjects provides at least $87 \%$ power to test the primary hypothesis. Intent-to-treat analyses will be performed, which include all patients enrolled in the registry regardless of whether the fast-track protocol is completed successfully. Subjects will be considered enrolled when the delivery catheter is inserted into the vasculature. Continuous data will be reported using mean and standard deviation or median, minimum, and maximum, depending on normality assumptions. Categorical data will be reported with counts and percentages. The incidence of major adverse events will be compared to the TPG by calculating a one-sided $95 \%$ Wilson upper confidence interval limit. Subgroup analyses will be performed for: a) patients who complete the fast-track EVAR protocol, b) patients who undergo bilateral percutaneous access but do not complete the fasttrack EVAR protocol, and c) patients who do not undergo bilateral percutaneous access.

\section{Study progress}

The first patient in this study was enrolled in October 2014 and enrollment is anticipated to continue through mid-2016. As of October 4, 2015, 149 patients have been enrolled at over 25 sites in the United States.

\section{Discussion}

The recent development of ultra low-profile stent grafts enables EVAR using least invasive methods. However, strict patient selection criteria are crucial to improving outcomes of a fast-track EVAR program. Ideal candidates have access vessels free of heavy calcification or extreme tortuosity and have no major risk factors for prolonged procedure or hospitalization such as ruptured AAA, renal failure, and severe comorbid conditions. Bilateral percutaneous vascular access results in higher technical success, less blood loss, fewer complications, and shorter hospital stay compared to surgical cutdown [7, 9-15]. Avoidance of general anesthesia is associated with lower rates of mortality and morbidity and shorter intensive care unit and hospital stays compared to regional anesthesia [16]. Next-day hospital discharge with no ICU stay has obvious cost benefits, provided that patient safety is not compromised. The observed advantages of each separate component may potentially yield synergistic clinical and cost benefits when utilized collectively in a structured fast-track EVAR protocol. The results of the LIFE study with the Ovation Prime stent graft are anticipated to be available in late 2016.

\section{Competing interests}

Zvonimir Krajcer, MD is an interventional cardiologist at Texas Heart Institute in Houston, Texas. He is Co-Director, Peripheral Vascular Disease Service at Texas Heart Institute, affiliated with CHI St. Luke's Health - Baylor St. Luke's Medical Center, and a Clinical Professor at Baylor College of Medicine. He has disclosed that he is a paid consultant to Trivascular and National Principal Co-Investigator of the LIFE study.

Venkatesh G. Ramaiah, MD, FACS, is a vascular surgeon at the Arizona Heart Institute and Hospital in Phoenix, Arizona. He is Director of Research at the Arizona Heart Institute and Medical Director of the Arizona Heart Hospital. He has disclosed that he is a paid consultant to TriVascular and National Principal Co-Investigator of the LIFE study.

Meredith Huetter leads the Medical Affairs organization at TriVascular, Inc. Trivascular is the study sponsor for the LIFE study.

\section{Authors' contributions}

$Z K, V R$, and $M H$ were involved in the conception and design of the study, equally participated in drafting the manuscript, and provided final approval for publication.

\section{Acknowledgements}

The authors thank Larry E. Miller, PhD for editorial assistance and critical review.

\section{Author details}

${ }^{1}$ St. Luke's Episcopal Hospital, Houston, TX, USA. ²Arizona Heart Institute, Phoenix, AZ, USA. ${ }^{3}$ TriVascular, Inc., Santa Rosa, CA, USA. 


\section{References}

1. Greenhalgh RM, Brown LC, Powell JT, Thompson SG, Epstein D, Sculpher MJ. Endovascular versus open repair of abdominal aortic aneurysm. N Engl J Med. 2010:362:1863-71.

2. Lederle FA, Freischlag JA, Kyriakides TC, Padberg Jr FT, Matsumura JS, Kohler $T R$, et al. Outcomes following endovascular vs open repair of abdominal aortic aneurysm: a randomized trial. JAMA. 2009;302:1535-42.

3. Muehling BM, Ortlieb L, Oberhuber A, Orend KH. Fast track management reduces the systemic inflammatory response and organ failure following elective infrarenal aortic aneurysm repair. Interact Cardiovasc Thorac Surg. 2011;12:784-8

4. Muehling BM, Halter G, Lang G, Schelzig H, Steffen P, Wagner F, et al. Prospective randomized controlled trial to evaluate "fast-track" elective open infrarenal aneurysm repair. Langenbecks Arch Surg. 2008;393:281-7.

5. Murphy MA, Richards T, Atkinson C, Perkins J, Hands LJ. Fast track open aortic surgery: reduced post operative stay with a goal directed pathway. Eur J Vasc Endovasc Surg. 2007;34:274-8.

6. Muehling B, Schelzig H, Steffen P, Meierhenrich R, Sunder-Plassmann L, Orend $\mathrm{KH}$. A prospective randomized trial comparing traditional and fast-track patient care in elective open infrarenal aneurysm repair. World J Surg. 2009;33:577-85.

7. Krajcer Z, Strickman N, Mortazavi A, Dougherty K. Single-center experience of percutaneous abdominal aortic aneurysm repair with local anesthesia and conscious sedation: technique and results. J Cardiovasc Surg (Torino). 2012;53:695-706.

8. Mehta M, Valdes FE, Nolte T, Mishkel GJ, Jordan WD, Gray B, et al. Safety APCStEt, Effectiveness of the Ovation Abdominal Stent Graft System I: One-year outcomes from an international study of the Ovation Abdominal Stent Graft System for endovascular aneurysm repair. J Vasc Surg. 2014:59:65-73-e61-63.

9. Haulon S, Hassen Khodja R, Proudfoot CW, Samuels E. A systematic literature review of the efficacy and safety of the Prostar XL device for the closure of large femoral arterial access sites in patients undergoing percutaneous endovascular aortic procedures. Eur J Vasc Endovasc Surg. 2011:41:201-13.

10. Al-Khatib WK, Zayed MA, Harris EJ, Dalman RL, Lee JT. Selective use of percutaneous endovascular aneurysm repair in women leads to fewer groin complications. Ann Vasc Surg. 2012;26:476-82.

11. Jaffan AA, Prince EA, Hampson CO, Murphy TP. The Preclose Technique in Percutaneous Endovascular Aortic Repair: A Systematic Literature Review and Meta-analysis. Cardiovasc Intervent Radiol. 2013;36:567-77.

12. Bensley RP, Hurks R, Huang Z, Pomposelli F, Hamdan A, Wyers M, et al. Ultrasound-guided percutaneous endovascular aneurysm repair success is predicted by access vessel diameter. J Vasc Surg. 2012;55:1554-61.

13. Nelson PR, Kracjer Z, Kansal N, Rao V, Bianchi C, Hashemi H, et al. A multicenter, randomized, controlled trial of totally percutaneous access versus open femoral exposure for endovascular aortic aneurysm repair (the PEVAR trial). J Vasc Surg. 2014:59:1181-93.

14. Krajcer Z, Matos JM. Totally percutaneous endovascular abdominal aortic aneurysm repair: 30-day results from the independent access-site closure study of the PEVAR trial. Tex Heart Inst J. 2013;40:560-1.

15. Krajcer Z, Nelson P, Bianchi C, Rao V, Morasch M, Bacharach J. Percutaneous endovascular abdominal aortic aneurysm repair: methods and initial outcomes from the first prospective, multicenter trial. J Cardiovasc Surg (Torino). 2011;52:651-9.

16. Ruppert V, Leurs LJ, Rieger J, Steckmeier B, Buth J, Umscheid T, et al. Riskadapted outcome after endovascular aortic aneurysm repair: analysis of anesthesia types based on EUROSTAR data. J Endovasc Ther. 2007;14:12-22.

\section{Submit your next manuscript to BioMed Central and we will help you at every step:}

- We accept pre-submission inquiries

- Our selector tool helps you to find the most relevant journal

- We provide round the clock customer support

- Convenient online submission

- Thorough peer review

- Inclusion in PubMed and all major indexing services

- Maximum visibility for your research

Submit your manuscript at www.biomedcentral.com/submit

) Biomed Central 